\title{
sciendo
}

\author{
JOLANTA HERDA ${ }^{1}$, PIOTR OKOŃSKI ${ }^{1}$, AGNIESZKA PARFIN", \\ KRYSTIAN WDOWIAK ${ }^{2}$, MAREK KOS ${ }^{1}$
}

\section{Thyroid diseases and mental illness together with behavioural disorders versus mental illness together with behavioural disorders and thyroid diseases}

\begin{abstract}
Introduction. Numerous authors have undertaken research on the coexistence of mental health disorders and thyroid disease. They have not been able to clearly demonstrate which illness came first.

Aim. The main purpose of this work is to asses the coexistence of thyroid disease with mental health conditions and disorders in behaviour. This work is based on a retrospective study and has shown frequent coexistence of thyroid disease with mental health or behaviour disorders.

Material and methods. The research method was a retrospective study carried out on the basis of medical records of patients of primary care clinics in the city of Lublin. The criterion for qualifying patients for the study was having a diagnosis, according to ICD 10, from at least one of the following groups: thyroid diseases E03-E07, mental health conditions F00-F 99 and behavioral disorders R44-R46.

Results. In total, 243 patients were qualified for the study. In this group 193 people are women and the remaining 50 are men. Among patients with isolated diseases, $28 \%$ of them have only diagnosed thyroid disease; every third patient (30\%) has diagnosed mental health illness or behavioural disorders. The Fisher test showed a relationship between thyroid diseases and mental health conditions including behavioural disorders $(\mathrm{p}=0.0000)$. A group of people with hypothyroidism in the course of Hashimoto's disease has been identified. The results of the prevalence of the disease were observed dividing by gender and age. Hashimoto's disease occurs in the group of $15 \%$ women and $4 \%$ men. Pearson's $\mathrm{Chi}^{2}$ test showed a relationship between the incidence of Hashimoto's disease and gender $(p=0.037)$. The quota coefficient showed that this relationship is weak $(0.13)$. The disease is more common in women.

Conclusions. There is a close relationship between the incidence of thyroid disease and mental health illness, including behavioural disorders. Patients with co-morbidity are significantly more likely to present mental illnesses and disorders. The dominance of mental illnesses and disorders is three times higher compared to thyroid diseases.
\end{abstract}

Keywords: thyroid diseases, mental disorders, behavioural disorders, Hashimoto disease.

DOI: $10.2478 /$ pjph-2021-0007

\section{INTRODUCTION}

As famous as the paintings of Vincent van Gogh in the world of art, there are well-known mental health disorders in medicine, as a cause why he cut his ear. Phases of peace and work, when painting was a therapy for him, were mixed with attacks of incorrect behaviour. Despite the constant progress in science, the human brain still remains partly a mystery to doctors and scientists. In the nerve cells and the connections between them, our personality, thoughts and feelings are contained. However, we rarely realize, how the foundation, on which our awareness is relying, is fragile. Sometimes one stressful situation, accident or genetic mutation, invisible from the outside, is enough for our behaviour or personality to change completely. In this work we want to emphasize the fact how complicated are the processes taking place in the central nervous system and their comprehensive impact on the entire human body. This can be seen in the example of the thyroid, which, although is located outside the CNS, is controlled by the thyrotropin produced by the pituitary. Numerous authors, who have undertaken research in the area of coexistence of mental health disorders and thyroid diseases, have not been able to clearly demonstrate which of these disorders develops first.

The area of mental health is an important element of both, definition of health and health models. The World Health Organization (WHO) defines mental health as a well-being in which an individual realizes his or her abilities, is able to cope with a variety of life situations, is able to participate in social life and work productively. Mental health is the foundation of a person's well-being and effective functioning in society. In this perspective, mental health means much more than just lack of mental disorders [1].

Existing data and forecasts on mental health indicate that mental disorders are a serious and growing problem worldwide [2]. Depression and alcohol-related disorders are the two most common mental disorders in the world. Depression is one of the 20 most 
important causes of disability in the world. The disease affects 120 million people and the number is constantly increasing.

Hashimoto's disease is a chronic, inflammatory, autoimmune thyroid disease $[3,4]$. It is now considered the most common autoimmune disease in the world and also the most common cause of hypothyroidism in areas rich in iodine [5,6]. Depressive disorders are often associated with Hashimoto's disease, especially in women in the postpartum and peri-partum period [7]. In the group of patients with elevated titer antithyroid autoantibodies, an increased risk of bipolar affective disorder with rapid phase change and obsessive-compulsive disorder was also described [8-12].

\section{AIM}

The main purpose of this work is to assess the coexistence of thyroid disease with mental health illness, including behavioural disorders.

Specific objectives:

1. To assess the prevalence of thyroid diseases or mental health illness, including behavioural disorders.

2. Determination of a dominant diagnosis in a common group of diagnoses included in the study.

3. Assessment of the relationship between the occurrence of thyroid diseases and gender and age; and between the common occurrence of thyroid diseases and mental health illness, including behavioural disorders and gender and age.

4. The coexistence of Hashimoto's disease with mental health disorders with behavioural disorders.

5. Hashimoto's disease depending on gender and age.

6. TSH and FT4 levels depending on gender and age.

7. Other important features of the common course of mental health and behavioural disorders and thyroid diseases.

\section{MATERIAL AND METHODS}

The research method was a retrospective study carried out on the basis of medical records of patients of one primary care clinics in the city of Lublin. The data was collected in the period from IV quarter 2017 to the end of I quarter 2020. At the end of March 2020, the total number of patients at the clinic was 2061. The most numerous group were young people between 20 and 39 years of age and constituted almost half of all (1026 people); the smallest group were patients over 75 years of age and there were only 12 of them - data based on the report of settlement of health services in basic health care confirmed by the National Health Fund.

The criterion for qualifying patients for the study was having a diagnosis, according to ICD 10, from at least one of the following groups: thyroid diseases E03-E07, mental health conditions F00-F99 and behavioral disorders R44-R46. The study group was formed by combining all diagnoses into one common range. The age of patients was divided into 7 sections: section I from 0 to 10 years; II - 11 to 21 years; III - 22 to 32 years; IV - 33 to 43 years; V -44 to 54 years; VI - 55 to 65 years; VII - over 65 years.

There was also performed the analysis of results for levels of TSH and FT4 hormones. Laboratory results were evaluated and classified into three groups: „standard”, ,,result below - decreased”, „result above - increased”, separately for TSH and FT4. The study also identified other coexisting diseases or disorders which occur in the studied population. This group includes: obesity, insulin resistance, type 2 diabetes, other endocrine disorders and cancer.
Computer programs were used for statistical analysis of the data. Statistica 13.0 PL Statsoft inc. (2017) was used to perform statistical analysis and multiple tables and Microsoft Excel 2010 PL Microsoft Corporation to edit tables. Fisher's test and Pearson's $\mathrm{Chi}^{2}$ test (if $\mathrm{p}<0.05$ was considered to have a relationship between the data) were used to determine the occurrence of the relationship between the data. To determine the strength of the data relationship, the contingency coefficient and Cramer's V test were used.

\section{RESULTS}

Out of all the patients at the clinic (2061), thyroid diseases occurred in 169 (8.2\%), and mental health illness, including behavioural disorders, in 174 (8.4\%). Therefore, 243 patients were qualified for the study. In this group 193 people are women and the remaining 50 are men. Due to the place of residence: among women 181 of them live in the city and 12 in a village. In the group of men 47 live in the city and 3 in a village.

The leading aspect of the study was to indicate a possible relationship between the occurrence of thyroid diseases and mental health illness, including behavioural disorders. In this context, medical records of patients were evaluated in terms of individual thyroid diseases or mental health illness, as well as cases of their common occurrence. In relation to patients who were found to have a common occurrence of the diseases and disorders indicated, it was also determined which of them are predominant.

Among patients with isolated diseases, $28 \%$ of them have only diagnosed thyroid disease; every third patient (30\%) has diagnosed mental health illness or behavioural disorders. Whereas 101 people, which accounts for $42 \%$ of the surveyed population, were diagnosed as having a common occurrence of thyroid diseases together with mental health illness, including behavioural disorders. The last group is the largest one, so it can be concluded that in the studied population the co-occurrence of thyroid diseases and mental health illness, including behavioural disorders, dominates. Common disorders occur in $49 \%$ of women and $12 \%$ of men. A single group of thyroid disorders occurs in $78 \%$ of women and $36 \%$ of men. It can therefore be concluded that all these disorders are statistically significantly more common in the group of women.

The Fisher test showed a relationship between thyroid diseases and mental health conditions, including behavioural disorders $(p=0.0000)$. The contingency coefficient showed that this relationship is rather weak (0.38). In the group of patients with co-occurrence of thyroid diseases with mental health illness, including behavioural disorders, it was found that 73 patients were dominated by mental health disorders (which is $30 \%$ of the examined group) and in 28 patients thyroid diseases dominate (12\% of the examined group). In the case of co-occurrence of the above mentioned disorders, it was found that mental disorders occur as a dominant diagnosis three times more often.

Relationships between the occurrence of thyroid diseases and gender and age were assessed. The Fisher test showed the relationship between the incidence of thyroid diseases and gender $(p=0.0000)$. The contingency coefficient showed that this relation is rather weak $(0.35)$. Pearson's $\mathrm{Chi}^{2}$ test showed a relationship between the incidence of thyroid disease and the age of patients $(p=0.018)$. The contingency coefficient showed that this relationship is rather weak (0.24).

The common occurrence of thyroid diseases and mental health conditions, including behavioural disorders, indicates 
some statistically significant relationships with gender and age. The Fisher test showed a relationship between the co-occurrence of thyroid disease and mental health conditions, including behavioural disorders, and gender $(\mathrm{p}=0.0000)$. The contingency coefficient showed that this relationship is rather weak (0.29). Pearson's Chi ${ }^{2}$ test showed no correlation between the common occurrence of thyroid diseases and mental health disorders and the age group of patients $(\mathrm{p}=0.19)$.

A group of people with hypothyroidism in the course of Hashimoto's disease has been identified. The results of the prevalence of the disease were observed by gender and age. Hashimoto's disease occurs in the group of $15 \%$ women and $4 \%$ men.

It was observed that gender had a significant statistical influence on the prevalence of Hashimoto's disease. Pearson's $\mathrm{Chi}^{2}$ test showed a relationship between the incidence of Hashimoto's disease and gender $(\mathrm{p}=0.037)$. The quota coefficient showed that this relationship is weak $(0.13)$. The disease is more common in women.

There were no people with Hashimoto's disease between the ages of 0 and 10 , and only 1 man between the ages of 11 and 21. In the 22-32 age group women with Hashimoto's disease constitute $17 \%$ and only 1 man. Discussion of the prevalence of the disease in the next two age ranges indicates a much higher incidence of autoimmune thyroiditis among women aged 33-54 years. The diagrams below are used to illustrate the prevalence of the disease among women of postnatal and perimenopausal age, and so in the group of 33-43 years every third woman is affected by the disease.

The age of patients as a single determinant in comparison with the prevalence of Hashimoto's disease indicates a statistically significant relationship. Pearson's $\mathrm{Chi}^{2}$ test showed a relationship between the incidence of Hashimoto's disease and the age group of patients $(\mathrm{p}=0.0023)$. The quota coefficient showed that this relationship is rather weak (0.28).

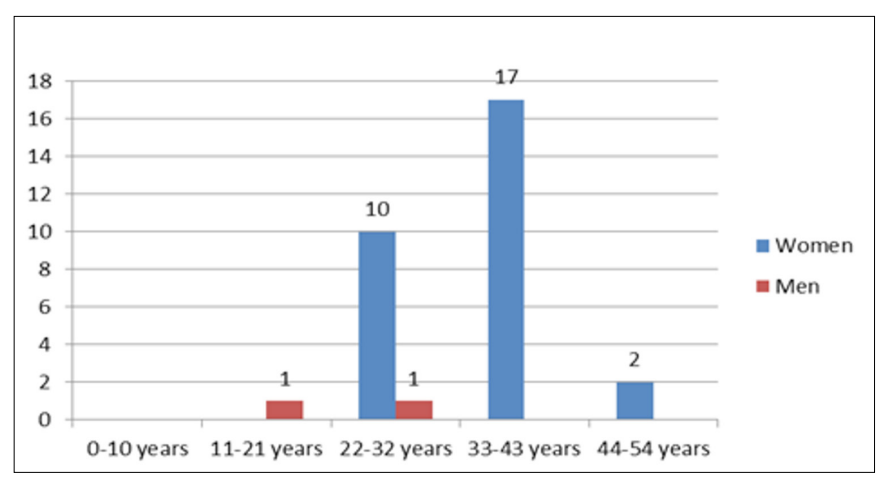

FIGURE 1. Poles opinon on the hierarchy of professioanl prestige based on the arithmetic mean.

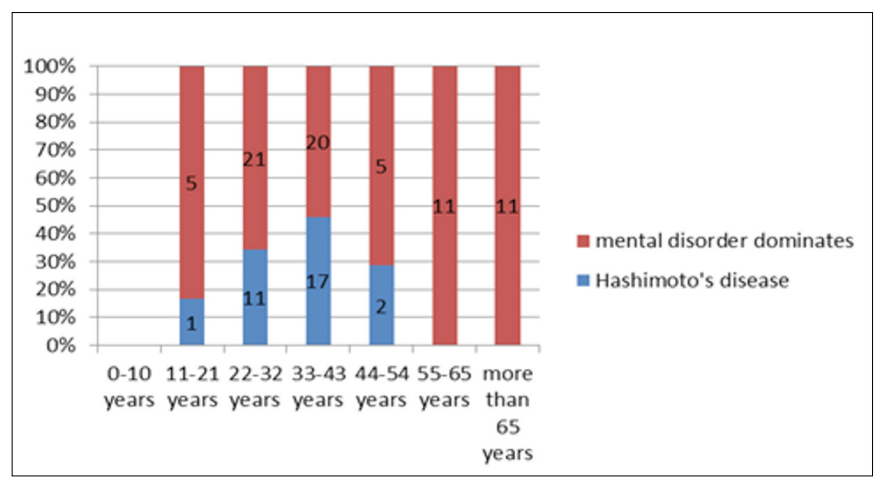

FIGURE 2. Hashimoto's disease in coexistence with mental health illness including behavioural disorders and age.

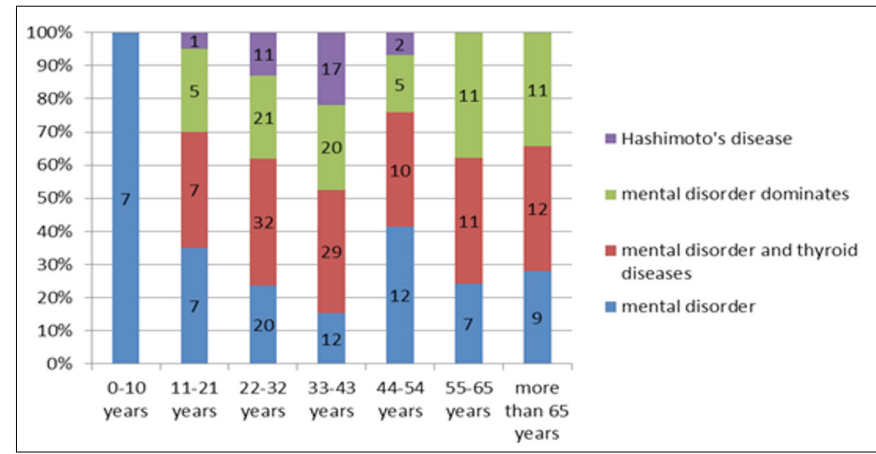

FIGURE 3. Hashimoto's disease and age group mental health illness including behavioural disorders.

The study also identified other coexisting diseases or disorders which, apart from thyroid diseases and mental health illness, including behavioural disorders, occur in the studied population. This group includes: obesity, insulin resistance, type 2 diabetes, other endocrine disorders and cancer. Among the examined persons there are pregnant women and people with a family history of thyroid diseases. It is important to emphasize the fact that depressions appear in women in the perinatal and perimenopausal period. These diseases are also associated with an increased risk of Hashimoto disease. In the literature we can find that the cases of severe, atypical or drugresistant depression and depressive disorders occurring in women in early pregnancy, postpartum or peri-partum period are particularly important here $[8,13]$.

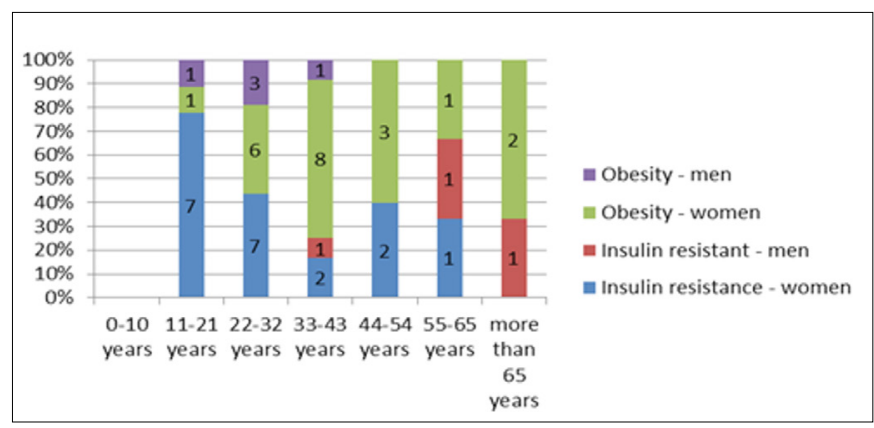

FIGURE 4. Insulin resistance and obesity according to gender and age.

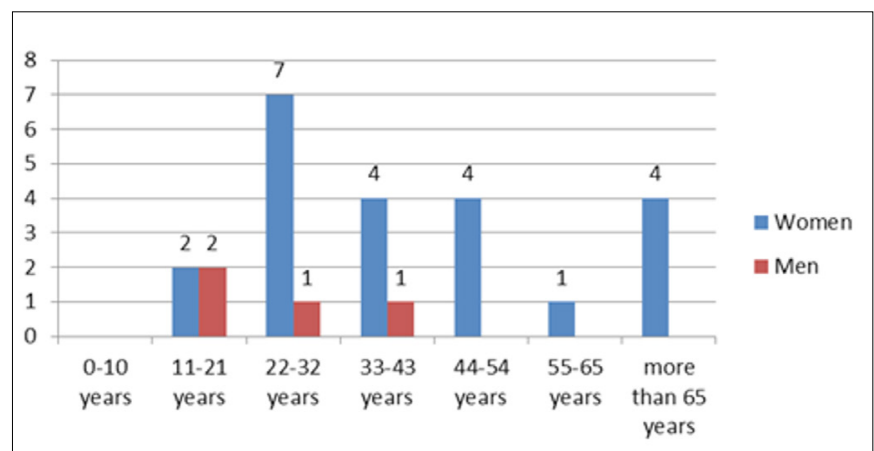

FIGURE 5. Other endocrine disorders according to gender and age.

Particularly noteworthy is the family history of thyroid diseases and the co-morbidity of thyroid diseases and mental illnesss/disorders in the group of younger people whose medical records have been assessed, especially women aged 11-43 years. In the studied group of patients, TSH and FT4 levels were assessed. As a result of statistical analysis, the relationship between lowered and elevated hormone levels and age was observed. Reduced TSH levels are more frequent in patients aged 22-32 and 33-43 years. 
TABLE 1. Age-related increased and decreased TSH level.

\begin{tabular}{lccccccc}
\hline \hline \multirow{2}{*}{ TSH level } & \multicolumn{8}{c}{ Age } \\
\cline { 2 - 8 } & $\begin{array}{c}\mathbf{0 - 1 0} \\
\text { years }\end{array}$ & $\begin{array}{c}\mathbf{1 1 - 2 1} \\
\text { years }\end{array}$ & $\begin{array}{c}\mathbf{2 2 - 3 2} \\
\text { years }\end{array}$ & $\begin{array}{c}\mathbf{3 3 - 4 3} \\
\text { years }\end{array}$ & $\begin{array}{c}\mathbf{4 4 - 5 4} \\
\text { years }\end{array}$ & $\begin{array}{c}\mathbf{5 5 - 6 5} \\
\text { years }\end{array}$ & $\begin{array}{c}\text { Over } \\
\mathbf{6 5} \text { years } \\
\text { old }\end{array}$ \\
\hline Increased & 0 & 3 & 16 & 12 & 6 & 2 & 3 \\
\hline Decreased & 0 & 3 & 14 & 18 & 0 & 5 & 4 \\
\hline
\end{tabular}

Pearson's $\mathrm{Chi}^{2}$ test showed no correlation between increased TSH levels and age $(\mathrm{p}=0.82$ ).

TABLE 2. Age-related increased and decreased FT4 level.

\begin{tabular}{lccccccc}
\hline \hline \multirow{2}{*}{ FT4 level } & \multicolumn{7}{c}{ Age } \\
\cline { 2 - 8 } & $\begin{array}{c}\mathbf{0 - 1 0} \\
\text { years }\end{array}$ & $\begin{array}{c}\mathbf{1 1 - 2 1} \\
\text { years }\end{array}$ & $\begin{array}{c}\mathbf{2 2 - 3 2} \\
\text { years }\end{array}$ & $\begin{array}{c}\mathbf{3 3 - 4 3} \\
\text { years }\end{array}$ & $\begin{array}{c}\mathbf{4 4 - 5 4} \\
\text { years }\end{array}$ & $\begin{array}{c}\mathbf{5 5 - 6 5} \\
\text { years }\end{array}$ & $\begin{array}{c}\text { Over } \\
\text { 65 years } \\
\text { old }\end{array}$ \\
\hline Increased & 0 & 0 & 12 & 7 & 1 & 3 & 1 \\
\hline Decreased & 0 & 4 & 15 & 11 & 9 & 4 & 3
\end{tabular}

Pearson's $\mathrm{Chi}^{2}$ test showed no correlation between decreased FT4 level and age $(\mathrm{p}=0.33)$.

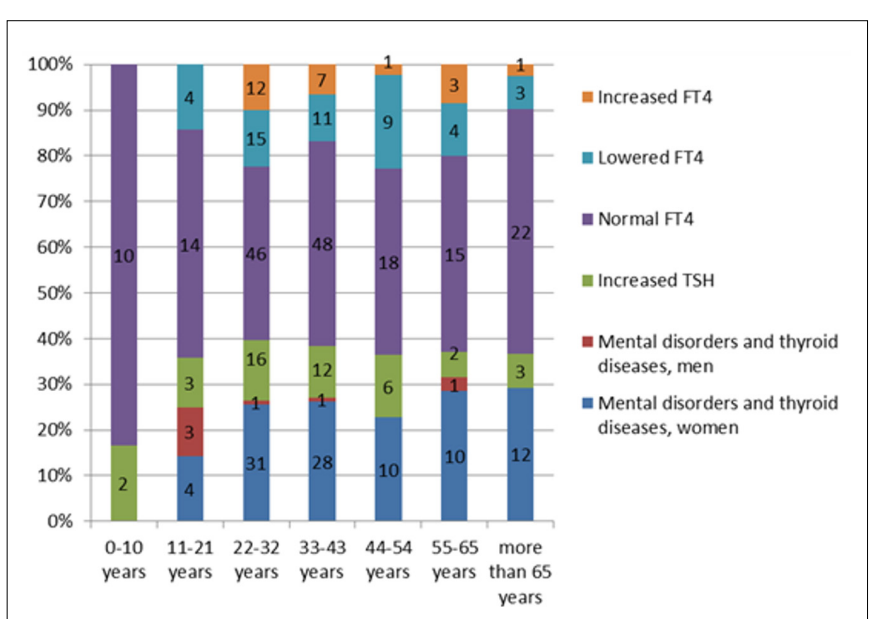

FIGURE 6. TSH and FT4 levels in mental disorders and thyroid diseases versus age $(p=0.16)$.

Children from 0 to 10 years of age were collected in the first compartment. There were 6 females and 4 males in the first age range. Single diseases or disorders: thyroid diseases ( 2 women, 1 man); mental health illness including behavioural disorders (4 women, 3 men), common disorders (thyroid diseases and mental health illness, including behavioural disorders -0$)$.

In the second age group, from 11 to 21 years of age, there were 10 women and 8 men. Single disease or disorders: thyroid diseases ( 4 women); mental health illness including behavioural disorders ( 2 women, 5 men), common disorders (4 women, 3 men; dominant - 5 mental illness/behavioural disorders and 2 thyroid diseases).

In the third age range, there were 58 women and 15 men between the ages of 22 and 32. Single diseases or disorders: thyroid (15 women; 6 men); mental health illness including behavioural disorders (12 women, $8 \mathrm{men}$ ), common disorders (31 women, 1 man; the dominant one - 21 mental illness/ behavioural disorders and 11 people with thyroid diseases).

In the fourth group there were 58 women and 8 men between the ages of 33 and 43. Single diseases or disorders: thyroid (23 women; 2 men); mental and behavioural diseases/ disorders ( 7 women, 5 men), common disorders (28 women, 1 man; dominant - 20 mental diseases/behavioural disorders and 9 thyroid diseases).
TABLE 3. Age-related TSH and FT4 level.

\begin{tabular}{ccccccccc}
\hline \multirow{2}{*}{$\begin{array}{c}\text { Hormone } \\
\text { levels }\end{array}$} & $\begin{array}{c}\text { 0-10 } \\
\text { years }\end{array}$ & $\begin{array}{c}\mathbf{1 1 - 2 1} \\
\text { years }\end{array}$ & $\begin{array}{c}\mathbf{2 2 - 3 2} \\
\text { years }\end{array}$ & $\begin{array}{c}\mathbf{3 3 - 4 3} \\
\text { years }\end{array}$ & $\begin{array}{c}\mathbf{4 4 - 5 4} \\
\text { years }\end{array}$ & $\begin{array}{c}\mathbf{5 5 - 6 5} \\
\text { years }\end{array}$ & $\begin{array}{c}\text { More } \\
\text { than 65 } \\
\text { years }\end{array}$ \\
\cline { 2 - 9 } TSH & standard & 10 & 12 & 43 & 36 & 22 & 15 & 19 \\
\cline { 2 - 9 } & decreased & 0 & 3 & 14 & 18 & 0 & 5 & 4 \\
\cline { 2 - 9 } & increased & 0 & 3 & 16 & 12 & 6 & 2 & 3 \\
\hline \multirow{2}{*}{ FT4 } & standard & 10 & 14 & 46 & 48 & 18 & 15 & 22 \\
\cline { 2 - 9 } & decreased & 0 & 4 & 15 & 11 & 9 & 4 & 3 \\
\cline { 2 - 9 } & increased & 0 & 0 & 12 & 7 & 1 & 3 & 1 \\
\hline
\end{tabular}

TABLE 4. Other coexisting diseases or disorders according to age group (M-men, W - women).

\begin{tabular}{|c|c|c|c|c|c|c|c|}
\hline \multirow{2}{*}{$\begin{array}{c}\text { Other coexisting } \\
\text { diseases } \\
\text { or disorders } \\
\text { and pregnancy: }\end{array}$} & \multicolumn{7}{|c|}{ Age group } \\
\hline & $\begin{array}{c}0-10 \\
\text { years }\end{array}$ & $\begin{array}{l}11-21 \\
\text { years }\end{array}$ & $\begin{array}{l}22-32 \\
\text { years }\end{array}$ & $\begin{array}{l}33-43 \\
\text { years }\end{array}$ & $\begin{array}{l}44-54 \\
\text { years }\end{array}$ & $\begin{array}{l}55-65 \\
\text { years }\end{array}$ & $\begin{array}{c}\text { More } \\
\text { than } 65 \\
\text { years }\end{array}$ \\
\hline $\begin{array}{l}\text { Hashimoto's } \\
\text { disease }\end{array}$ & 0 & $1 \mathrm{M}$ & $\begin{array}{c}10 \mathrm{~W} \\
1 \mathrm{M}\end{array}$ & $17 \mathrm{~W}$ & $2 \mathrm{~W}$ & 0 & 0 \\
\hline $\begin{array}{l}\text { A history } \\
\text { of thyroid disease }\end{array}$ & $1 \mathrm{~W}$ & $\begin{array}{l}2 \mathrm{~W} \\
2 \mathrm{M}\end{array}$ & $6 \mathrm{~W}$ & $\begin{array}{l}2 \mathrm{~W} \\
1 \mathrm{M}\end{array}$ & 0 & $1 \mathrm{~W}$ & 0 \\
\hline Cancer & 0 & 0 & $6 \mathrm{~W}$ & $\begin{array}{l}5 \mathrm{~W} \\
2 \mathrm{M}\end{array}$ & $3 \mathrm{~W}$ & $2 \mathrm{~W}$ & $4 \mathrm{~W}$ \\
\hline Obesity & 0 & $\begin{array}{l}1 \mathrm{~W} \\
1 \mathrm{M}\end{array}$ & $\begin{array}{l}6 \mathrm{~W} \\
3 \mathrm{M}\end{array}$ & $\begin{array}{l}8 \mathrm{~W} \\
1 \mathrm{M}\end{array}$ & $3 \mathrm{~W}$ & $1 \mathrm{~W}$ & $\begin{array}{l}2 \mathrm{~W} \\
1 \mathrm{M}\end{array}$ \\
\hline $\begin{array}{l}\text { Insulin } \\
\text { resistance }\end{array}$ & 0 & $7 \mathrm{~W}$ & $7 \mathrm{~W}$ & $\begin{array}{l}2 \mathrm{~W} \\
1 \mathrm{M}\end{array}$ & $2 \mathrm{~W}$ & $\begin{array}{l}1 \mathrm{~W} \\
1 \mathrm{M}\end{array}$ & 0 \\
\hline $\begin{array}{l}\text { Type } 2 \\
\text { diabetes }\end{array}$ & 0 & 0 & $\begin{array}{l}2 \mathrm{~W} \\
1 \mathrm{M}\end{array}$ & $4 \mathrm{~W}$ & 0 & $1 \mathrm{~W}$ & $1 \mathrm{~W}$ \\
\hline Pregnancy & 0 & 0 & $3 \mathrm{~W}$ & $4 \mathrm{~W}$ & 0 & 0 & 0 \\
\hline $\begin{array}{l}\text { Other endocrine } \\
\text { disorders }\end{array}$ & 0 & $\begin{array}{l}2 \mathrm{~W} \\
2 \mathrm{M}\end{array}$ & $\begin{array}{l}7 \mathrm{~W} \\
1 \mathrm{M}\end{array}$ & $\begin{array}{l}4 \mathrm{~W} \\
1 \mathrm{M}\end{array}$ & $4 \mathrm{~W}$ & $1 \mathrm{~W}$ & $4 \mathrm{~W}$ \\
\hline
\end{tabular}

In the fifth group there were 20 women and 8 men from 44 do 54 years old. Single diseases or disorders: thyroid ( 4 women; 2 men); mental and behavioural disorders ( 6 women, 6 men), common disorders (10 women, 0 men; dominant -5 mental diseases/ behavioural disorders and 5 patient suffering from thyroid diseases).

In the sixth group there were 19 women and 3 men between the ages of 55 and 65 . Single diseases or disorders: thyroid (3 women; 1 man); mental illness/ behavioural disorders (6 women, 1 man), common disorders (10 women, 1 man; dominant - 11 mental illness/behavioural disorders and no thyroid diseases).

In the last group there were people over 65 years old, 22 women and 4 men. Single diseases or disorders: thyroid (5 women; 0 men); mental illness/ behavioural disorders (5 women, 4 men), common disorders (12 women, 0 men; dominant - 11 mental illness/behavioural disorders and 1 thyroid disease);

\section{SUMMARY}

In this research, the authors point to the relationship between the co-occurrence of thyroid diseases and mental illnesses, including behavioural disorders, and this relationship has been confirmed by statistical analysis. Numerous Polish and international scientific studies confirm this fact. Also the 
co-occurrence of Hashimoto's disease and mood disorders has long been known. In earlier studies, the authors described neuropsychiatric consequences of thyroid dysfunction $[8,14]$, and nowadays the close relationship between these disorders is even more clearly emphasized [15-17]. It has been shown that both hyperthyroidism and hypothyroidism are associated with specific changes in the functioning of the central nervous system, which may result in disorders of attention, reaction rate, memory, information processing and affective disorders, mainly depression [18-22]. The observations made so far show that even mild thyroid dysfunctions are associated with changes in mood and cognitive function $[2,23,24]$.

The analysis of patients' medical records in this study showed some relationships between the incidence of Hashimoto's disease and determinants, such as gender and age. Discussion of the prevalence of the disease depending on age indicates a much higher incidence of autoimmune thyroiditis among women aged 32-54 years. This phenomenon is influenced by physiological processes closely related to the hormonal economy in women, which is connected with the birth of a child and the perimenopausal period, and so in this group every third woman is affected by the described disease.

The prevalence of Hashimoto's disease in the population, according to various data, ranges from 4 to $25 \%[18,25]$. The peak of the disease is observed between the age of 40 and 60 [26]. Women are exposed up to 8 times more often in comparison to the risk of disease among men [27]. Carta et al. in their studies prove even six times higher risk of depressive disorders in the group of patients with Hashimoto's disease, regardless of thyroid dysfunction assessed by routine serological tests $[28,29]$.

Similar results were obtained by Ayhan et al., confirming the increased incidence of depressive disorders in patients with autoimmune thyroiditis. Their study showed that about $30 \%$ of patients with Hashimoto's disease in euthyroidism suffer from depressive disorders [30]. The level of thyroid hormones correlates with age and younger patients have lower TSH levels. In recent years, scientific studies have pointed out the relationship between disturbances in the secretion of thyroid hormones and the activity of neurotransmitter systems, especially the dopaminergic, noradrenergic and serotonergic systems, and the occurrence of depressive and cognitive disorders $[16,31]$.

\section{CONCLUSIONS}

1. There is a close relationship between the incidence of thyroid disease and mental health illness, including behavioural disorders.

2. In the group of people with co-occurring thyroid diseases and mental health illness, psychiatric disorder has been found to be the dominant diagnosis three times more often.

3. Gender has an impact on the incidence of thyroid diseases and on the cohabitation of thyroid diseases together with mental health illnesses, including behavioural disorders - it is women who fall ill more often, while age is not a statistical determinant.

4. The prevalence of Hashimoto's disease is influenced by both determinants, gender and age. They significantly translate into increased incidence rates in the group of women aged 22-43 years.
5. The assessment of TSH and FT4 levels indicated a relationship between decreased TSH values and age, consisting in an increased frequency of TSH levels below normal in the age group 22-43 years. However, confirmation of this relationship requires increasing the size of the study group.

6 . The prevalence of thyroid diseases in the clinic's patient population is $8.2 \%$, and of mental health illness, including behavioural disorders is $8.4 \%$.

The authors of this work have attempted to find an answer to the question which of the diseases: thyroid or mental one appears first? Basing only on the fact of dominating, in the common group of diseases, one of them, one should point to mental illnesses and disorders. In order to clarify, it would be important to deepen the methodology of the study. This study is the right way to plan the next one in more detail and to continue the main idea.

\section{REFERENCES}

1. The World Health Report: 2001. Mental Health: New Understanding, New Hope. Geneva: World Health Organization; 2001.

2. The Global Burden of Disease: 2004 Update. 2008 Geneva: World Health Organization; 2008.

3. Encyklopedia PWN. [http://encyklopedia.pwn.pl/haslo/Ha-1.shimotochoroba;3910296.html]

4. Hashimoto H. Zur Kenntniss der lymphomatosen Verande-2. rung der Schilddruse (struma lymphomatosa). Arch Klin Chir. 1912;97:219-48.

5. Antonelli A, Ferrari SM, Corrado A, et al. Autoimmune thyroid disorders. Autoimmun Rev. 2015;14(2):174-80.

6. Duntas L. The Role of iodine and selenium in autoimmune thyroiditis. Horm Metab Res. 2015;47(10):721-6.

7. Migdal AL, Hennessey JV. Psychiatric disorders and thyroid disease. In: Endocrine secrets. Wyd. 6 Philadelphia. Pensylwania: Elsevier Saunders; 2013.

8. Broniarczyk-Czarniak M.Zaburzenia psychiczne współistniejące z chorobą Hashimoto - przegląd piśmiennictwa. Varia Medica. 2018;(2)1:83-90.

9. Lin IC, Chen HH, Yeh SY, et al. Risk of depression, chronic morbidities, and 1-thyroxine treatment in Hashimoto thyroiditis in Taiwan: A nationwide cohort study. Medicine (Baltimore). 2016;95(6):e2842.

10. Lin CL, Yang SN, Shiah IS. Acute mania in a patient with hypothyroidism resulting from Hashimoto's Thyroiditis. Gen Hosp Psychiatry. 2013;35(6):683.e1-683.e2.

11. Mohamadi A, Davoodi-Makinejad M, Azimi A, Naf-issi S. Personality characteristics in MS patients: The role of avoidant personality. Clin Neurol Neurosurg. 2016;144:23-7.

12. Sierra P, Cámara R, Tobella H, Livianos L. What is the real significance and management of major thyroid disorders in bipolar patients? Rev Psiquiatr Salud Ment. 2014;7:88-95.

13. Bocchetta A, Traccis F, Mosca E, et al. Bipolar disorder and antithyroid antibodies: review and case series. Int J Bipolar Disord. 2016;4(1):5.

14. Lu T, Zhou Z, Wu A, et al. Febrile Hashimoto's encephalopathy associated with Hashitoxicosis. Acta Neurol Belg. 2015;115(4):811-3.

15. Duntas LH, Maillis A. Hypothyroidism and depression: Salient aspects of pathogenesis and management. Minerva Endocrinol. 2013;38:365-77.

16. Kamble MT, Nandedkar PD, Dharme PV, et al. Thyroid function and mental disorders: An insight into the complex interaction. J Clin Diagn Res 2013;7:11-4.

17. Duntas L. The Role of iodine and selenium in autoimmune thyroiditis Horm Metab Res. 2015;47(10):721-6.

18. Bjoro T, Holmen J, Kruger O, et al. Prevalence of thyroid disease, thyroid dysfunction and thyroid peroxidase antibodies in a large, unselected population. The Health Study of Nord-Trondelag (HUNT). Eur J Endocrinol. 2000;143(5):639-47.

19. Fugger G, Dold M, Bartova L, et al. Comorbid thyroid disease in patients with major depressive disorder - results from the European Group for the Study of Resistant Depression (GSRD). Eur Neuropsychopharmacol. 2018;28(6):752-60.

20. Kirim S, Keskek SO, Köksal F, et al. Depression in patients with euthyroid chronic autoimmune thyroiditis. Endocr J. 2012;59(8):705-8. 
21. Degner D, Haust M, Meller J, et al. Association between autoimmune thyroiditis and depressive disorder in psychiatric outpatients. Eur Arch Psychiatry Clin Neurosci. 2015;265(1):67-72.

22. Koros C, Economou A, Mastorakos G, et al. A selective memory deficit caused by autoimmune encephalopathy associated with Hashimoto thyroiditis. Cogn Behav Neurol. 2012;25(3):144-8.

23. Hendrick VC, Garrick TR. Endocrine and metabolic disorders. In: Kaplan \& Sadock's comprehensive textbook of psychiatry. Seventh edition on CD-ROM. Pensylwania: Lippincott Williams \& Wilkins; 2000.

24. Joffe RT, Pearce EN, Hennessey JV, et al. Subclinical hypothyroidism, mood, and cognition in older adults: A review. Int $\mathrm{J}$ Geriatr Psychiatry. 2013;28:111-8

25. Melmed S, Polonsky K, Larsen P, Kronenberg H. WILLIAMS Textbook of Endocrinology 13th Edition Elsevier; 2015.

26. Delemer B, Aubert JP, Nys P, et al. An observational study of the initial management of hypothyroidism in France: the ORCHIDÉE study. Eur J Endocrinol. 2012;167(6):817-23.

27. Caturegli P, De Remigis A, Rose NR. Hashimoto thyroiditis: clinical and diagnostic criteria. Autoimmun Rev. 2014;13(4-5):391-7.

28. Carta MG, Hardoy MC, Carpiniello B, et al. A case control study on psychiatric disorders in Hashimoto disease and Euthyroid Goitre: Not only depressive but also anxiety disorders are associated with thyroid autoimmunity. Clin Pract Epidemiol Ment Health. 2005;(1):23.

29. Uysal HB, Ayhan M. Autoimmunity affects health-related quality of life in patients with Hashimoto's thyroiditis. Kaohsiung J Med Sci. 2016;32(8):427-33.

30. Ayhan MG, Uguz F, Askin R, et al. The prevalence of depression and anxiety disorders in patients with euthyroid Hashimoto's thyroiditis: a comparative study. Gen Hosp Psychiatry. 2014;36(1):95-8.

31. Joy Mathew C, Jose MT, Elshaikh AO, et al. Is hyperthyroidism a possible etiology of early onset dementia? Cureus. 2020;12(9):e10603.

\section{Corresponding author}

Dr Jolanta Herda

Chair and Department of Public Health, Medical Univeisty of Lublin

1 Chodźki St., 20-093 Lublin

E-mail: zdrowie.publiczne@umlub.pl 